\title{
Unexpected Link between the Template Purification Solvent and the Structure of Titanium Dioxide Hollow Spheres
}

\author{
Tamás Gyulavári ${ }^{1,2} \mathbb{D}$, Kata Kovács ${ }^{2}$, Klára Magyari ${ }^{1,3} \mathbb{D}$, Kornélia Baán ${ }^{2}$, Anna Szabó ${ }^{2}$, Gábor Veréb ${ }^{1,4}, * \mathbb{D}$, \\ Zsolt Pap 1,3,5,* and Klara Hernadi 1,2,*(D)
}

1 Research Group of Environmental Chemistry, Institute of Chemistry, University of Szeged, Tisza Lajos krt. 103, H-6720 Szeged, Hungary; gyulavarit@chem.u-szeged.hu (T.G.); klara.magyari@ubbcluj.ro (K.M.)

2 Department of Applied and Environmental Chemistry, University of Szeged, Rerrich tér 1, H-6720 Szeged, Hungary; kovacs.katus5@gmail.com (K.K.); kornelia.baan@chem.u-szeged.hu (K.B.); szabo.anna@chem.u-szeged.hu (A.S.)

3 Nanostructured Materials and Bio-Nano-Interfaces Center, Interdisciplinary Research Institute on Bio-Nano-Sciences, Babes-Bolyai University, Treboniu Laurian 42, RO-400271 Cluj-Napoca, Romania

4 Department of Process Engineering, Faculty of Engineering, University of Szeged, Moszkvai krt. 9, H-6725 Szeged, Hungary

5 Institute of Environmental Science and Technology, University of Szeged, Tisza Lajos krt. 103, H-6720 Szeged, Hungary

* Correspondence: verebg@mk.u-szeged.hu (G.V.); pzsolt@chem.u-szeged.hu (Z.P.); hernadi@chem.u-szeged.hu (K.H.); Tel.: +36-62-546-582 (G.V.); +36-62-544-338 (Z.P.); +36-62-544-626 (K.H.)

check for

updates

Citation: Gyulavári, T.; Kovács, K.;

Magyari, K.; Baán, K.; Szabó, A.;

Veréb, G.; Pap, Z.; Hernadi, K.

Unexpected Link between the

Template Purification Solvent and the Structure of Titanium Dioxide Hollow Spheres. Catalysts 2021, 11, 112.

https://doi.org/10.3390/catal11010112

Received: 7 December 2020

Accepted: 11 January 2021

Published: 14 January 2021

Publisher's Note: MDPI stays neutral with regard to jurisdictional clai$\mathrm{ms}$ in published maps and institutional affiliations.

Copyright: $\odot 2021$ by the authors. Licensee MDPI, Basel, Switzerland. This article is an open access article distributed under the terms and conditions of the Creative Commons Attribution (CC BY) license (https:// creativecommons.org/licenses/by/ $4.0 /)$.

\begin{abstract}
Carbon spheres were applied as templates to synthesize titanium dioxide hollow spheres. The templates were purified with either ethanol or acetone, and the effects of this treatment on the properties of the resulting titania were investigated. The photocatalytic activity of the catalysts was measured via the decomposition of phenol model pollutant under visible light irradiation. It was found that the solvent used for the purification of the carbon spheres had a surprisingly large impact on the crystal phase composition, morphology, and photocatalytic activity. Using ethanol resulted in a predominantly rutile phase titanium dioxide with regular morphology and higher photocatalytic activity $\left(\mathrm{r}_{0 \text {,phenol }}=3.9 \times 10^{-9} \mathrm{M} \cdot \mathrm{s}^{-1}\right)$ than that containing mainly anatase phase prepared using acetone $\left(\mathrm{r}_{0 \text {,phenol }}=1.2 \times 10^{-9} \mathrm{M} \cdot \mathrm{s}^{-1}\right)$, surpassing the photocatalytic activity of all investigated references. Based on infrared spectroscopy measurements, it was found that the carbon sphere templates had different surface properties that could result in the appearance of carbonate species in the titania lattice. The presence or absence of these species was found to be the determining factor in the development of the titania's properties.
\end{abstract}

Keywords: titanium dioxide; carbon spheres; hollow spheres; phenol; purification; ethanol; acetone

\section{Introduction}

When it comes to photocatalytic water treatment, titanium dioxide $\left(\mathrm{TiO}_{2}\right)$ remains the staple choice with good reason. The applicability of $\mathrm{TiO}_{2}$ in wastewater treatment has been extensively investigated with various pollutants, such as phenol [1-3], organic dyes [4], pesticides [5], and pharmaceuticals [6], or by inactivating bacteria in disinfection processes [3,7]. During these investigations, $\mathrm{TiO}_{2}$ photocatalysts were utilized either in suspension or in an immobilized state. When considering the latter, there are several promising publications about their practical application in pilot plants $[7,8]$. Despite a tremendous effort to identify a more efficient semiconductor, the good overall characteristics of $\mathrm{TiO}_{2}$ have not been overcome in practical applications. However, it has its limitations. The most important limitation is that without modifications, its efficiency often proves to be insufficient to replace existing technologies. In order to tackle this problem, numerous attempts have been made to increase photocatalytic activity. This includes 
(i) doping with various elements, (ii) sensitizing with dyes, (iii) modifying with noble metals, (iv) preparing composites/coupled semiconductors, and (v) synthesizing $\mathrm{TiO}_{2}$ with various morphologies [9-14]. A relatively novel approach to achieve this goal is to synthesize $\mathrm{TiO}_{2}$-based hollow spheres (HSs) since photocatalysts with such a morphology possess increased light-harvesting capabilities compared to solid spheres $[15,16]$. There are various methods to prepare $\mathrm{TiO}_{2} \mathrm{HSs}$ (e.g., hydrothermal, sonochemical, and templatebased) [17]. The most commonly applied method is the template removal method [18]. Among the most convenient template materials are carbon spheres (CSs) due to their environmentally friendly nature and high hydrophilicity, conveyed by polar $-\mathrm{OH}$ and $-\mathrm{C}=\mathrm{O}$ groups on their surface [18]. However, due to their synthesis method, it is usually necessary to purify them from the various contaminants (for example, aromatic compounds and oligosaccharides [19]) that form during the synthesis. It is known that applying solvents of different polarity can result in the formation of titanium dioxides with different crystal phase compositions and characteristics [20]. However, the effects of the solvents used for the purification of the templates on the properties of the as-prepared titania have been poorly investigated.

In our previous publication, we demonstrated that not only the synthesis conditions of $\mathrm{TiO}_{2}$ coating but also that the parameters applied during the preparation of CSs can significantly affect the properties of the resulting titania [21]. In this paper, we present the importance of the purification solvent by using either acetone or ethanol to eliminate the residual organic contaminants formed during the synthesis of CSs, since it was observed that this parameter might be the most crucial of all in our system.

\section{Results and Discussion}

\subsection{Textural Characterization}

X-ray diffraction patterns of the home-made $\left(\mathrm{TiO}_{2} \_\mathrm{HS} \_\mathrm{Ac}\right.$ and $\left.\mathrm{TiO}_{2} \_\mathrm{HS} \_\mathrm{EtOH}\right)$ and reference (Rutile-H2, Aeroxide P25, and Aldrich rutile which is a rutile phase $\mathrm{TiO}_{2}$ purchased from Sigma-Aldrich, Schnelldorf, Germany) titania are shown in Figure 1. For the sake of completeness, the X-ray diffraction patterns of the CSs purified either by acetone (CS_Ac) or ethanol (CS_EtOH), and the $\mathrm{TiO}_{2}-\mathrm{CS}$ composites (i.e., CSs coated with $\mathrm{TiO}_{2}$; $\mathrm{TiO}_{2}$ CCS_Ac and $\mathrm{TiO}_{2}$ CS_EtOH, respectively) were also recorded and shown in Supplementary Materials Figure S1. Crystal phase distributions, average primary crystallite sizes, and specific surface areas (SSA) are presented in Table 1. Reference photocatalysts were characterized in detail in our previous publication [22].

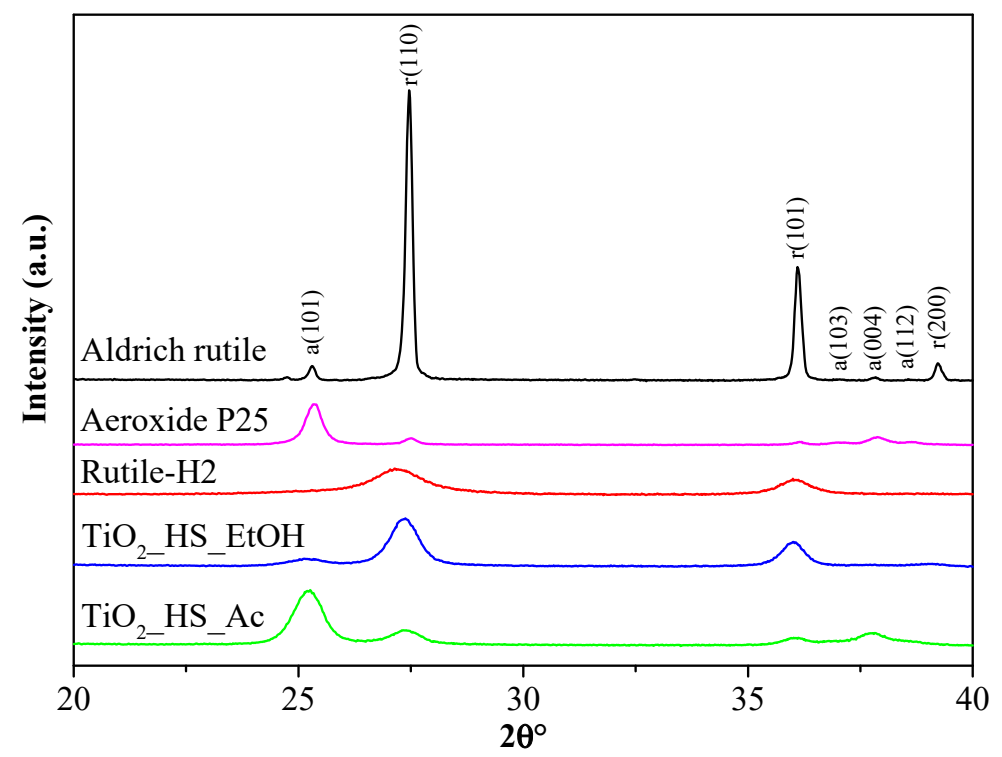

Figure 1. X-ray diffraction patterns of home-made and reference titanium dioxides. 
Table 1. Phase composition, average crystallite size, and specific surface area of the investigated titanium dioxides.

\begin{tabular}{|c|c|c|c|c|c|c|}
\hline \multirow{2}{*}{$\begin{array}{l}\text { Titanium- } \\
\text { Dioxide }\end{array}$} & \multicolumn{2}{|r|}{ Anatase } & \multicolumn{2}{|r|}{ Rutile } & \multirow[b]{2}{*}{$\begin{array}{l}\text { Specific Surface Area } \\
\left(\mathrm{m}^{2} \cdot \mathrm{g}^{-1}\right)\end{array}$} & \multirow[b]{2}{*}{$\mathrm{r}_{0, \text { phenol }}\left(10^{-9} \mathrm{M} \cdot \mathrm{s}^{-1}\right)$} \\
\hline & $w t \%$ & Particle Size (nm) & wt $\%$ & Particle Size (nm) & & \\
\hline $\mathrm{TiO}_{2} \_\mathrm{HS} \_\mathrm{Ac}$ & 79 & 12.3 & 21 & 11.7 & 51 & 1.2 \\
\hline $\mathrm{TiO}_{2}$ HSS_EtOH & 14 & 10.4 & 86 & 13.1 & 30 & 3.9 \\
\hline Rutile-H2 & $<1$ & - & $>99$ & 7.0 & 237 & 1.9 \\
\hline Aeroxide P25 & 90 & 25.4 & 10 & 40.0 & 49 & 1.6 \\
\hline Aldrich rutile & 4 & 315.0 & 96 & 315.0 & 3 & 3.7 \\
\hline
\end{tabular}

As a function of CS template purification solvent, the crystal phases of our homemade titania were remarkably different: $\mathrm{TiO}_{2} \_\mathrm{HS} \_$Ac contained predominantly anatase phase $(79 \mathrm{wt} \%)$, whereas $\mathrm{TiO}_{2} \_\mathrm{HS} \_\mathrm{EtOH}$ contained predominantly rutile phase $(86 \mathrm{wt} \%)$. The increased primary crystallite sizes and decreased specific surface areas $\left(\mathrm{TiO}_{2}\right.$ HS_Ac: $\left.\mathrm{D}_{\text {anatase }}=12.3 \mathrm{~nm}, \mathrm{SSA}=51 \mathrm{~m}^{2} \cdot \mathrm{g}^{-1} ; \mathrm{TiO}_{2} \_\mathrm{HS} \_\mathrm{EtOH}: \mathrm{D}_{\text {rutile }}=13.1 \mathrm{~nm}, \mathrm{SSA}=30 \mathrm{~m}^{2} \cdot \mathrm{g}^{-1}\right)$, compared to the reference starting material Rutile-H2 $\left(\mathrm{D}=7.0 \mathrm{~nm} ; \mathrm{SSA}=237 \mathrm{~m}^{2} \cdot \mathrm{g}^{-1}\right)$, can be explained by the result of calcination $\left(\mathrm{T}=400{ }^{\circ} \mathrm{C}, \mathrm{t}=4 \mathrm{~h}\right.$, heating rate $\left.=5^{\circ} \mathrm{C} \cdot \mathrm{min}^{-1}\right)$ that was used for the elimination of the CSs. The SSA of CS_Ac, CS_EtOH, $\mathrm{TiO}_{2}$ CS_Ac, and $\mathrm{TiO}_{2}$ CS_EtOH were also measured; their SSA values were $11,16,34$, and $27 \mathrm{~m}^{2} \cdot \mathrm{g}^{-1}$, respectively.

The significant effect of purification solvent on the properties of home-made titania was also observed during scanning electron microscopy (SEM; Figure 2a-d) and transmission electron microscopy (TEM; Figure 2e,f) measurements.

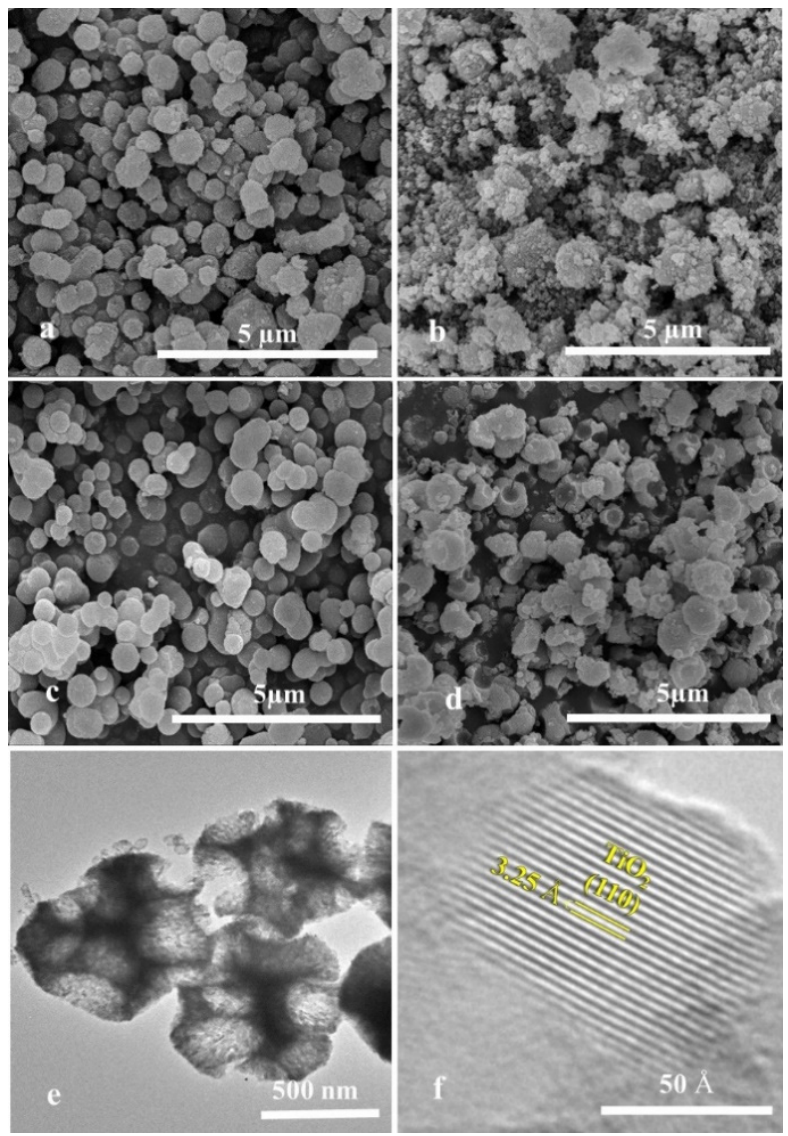

Figure 2. SEM micrographs of $\mathrm{TiO}_{2} \_\mathrm{HS} \_\mathrm{Ac}$ and $\mathrm{TiO}_{2} \_\mathrm{HS} \_\mathrm{EtOH}$ titania before $(\mathbf{a}, \mathbf{c})$ and after calcination $(\mathbf{b}, \mathbf{d})$, respectively, and TEM micrographs of $\mathrm{TiO}_{2} \_\mathrm{HS} \_\mathrm{EtOH}(\mathbf{e}, \mathbf{f})$. 
Following the coating process, the $\mathrm{TiO}_{2}$ layer evenly surrounded the CS templates, thus retaining their morphology (Figure 2a,c). However, after calcination, the structure of sample $\mathrm{TiO}_{2}$ HSS_Ac was damaged (Figure $2 b$ ), while in the case of sample $\mathrm{TiO}_{2} \_\mathrm{HS} \_\mathrm{EtOH}$, the spherical morphology remained mostly intact (Figure 2d). Consequently, TEM measurements were carried out on the latter sample (Figure 2e), and it was observed that it contained mainly hollow spheres, as intended. In Figure 2f, the presence of lattice fringes can be observed, and $3.25 \AA$ A was measured predominantly for the d-spacing values, which corresponded to the $\mathrm{TiO}_{2}$ (110) crystallographic planes (rutile phase). This demonstrates good agreement with the $\mathrm{X}$-ray diffractometry $(\mathrm{XRD})$ results. The predominantly rutile phase and hollow structure of the $\mathrm{TiO}_{2}$ HS_EtOH sample is presumed to contribute to the photocatalytic activity of this sample under visible light irradiation $[15,23]$.

\subsection{Photocatalytic Activity}

Photocatalytic degradation curves of phenol are shown in Figure 3.

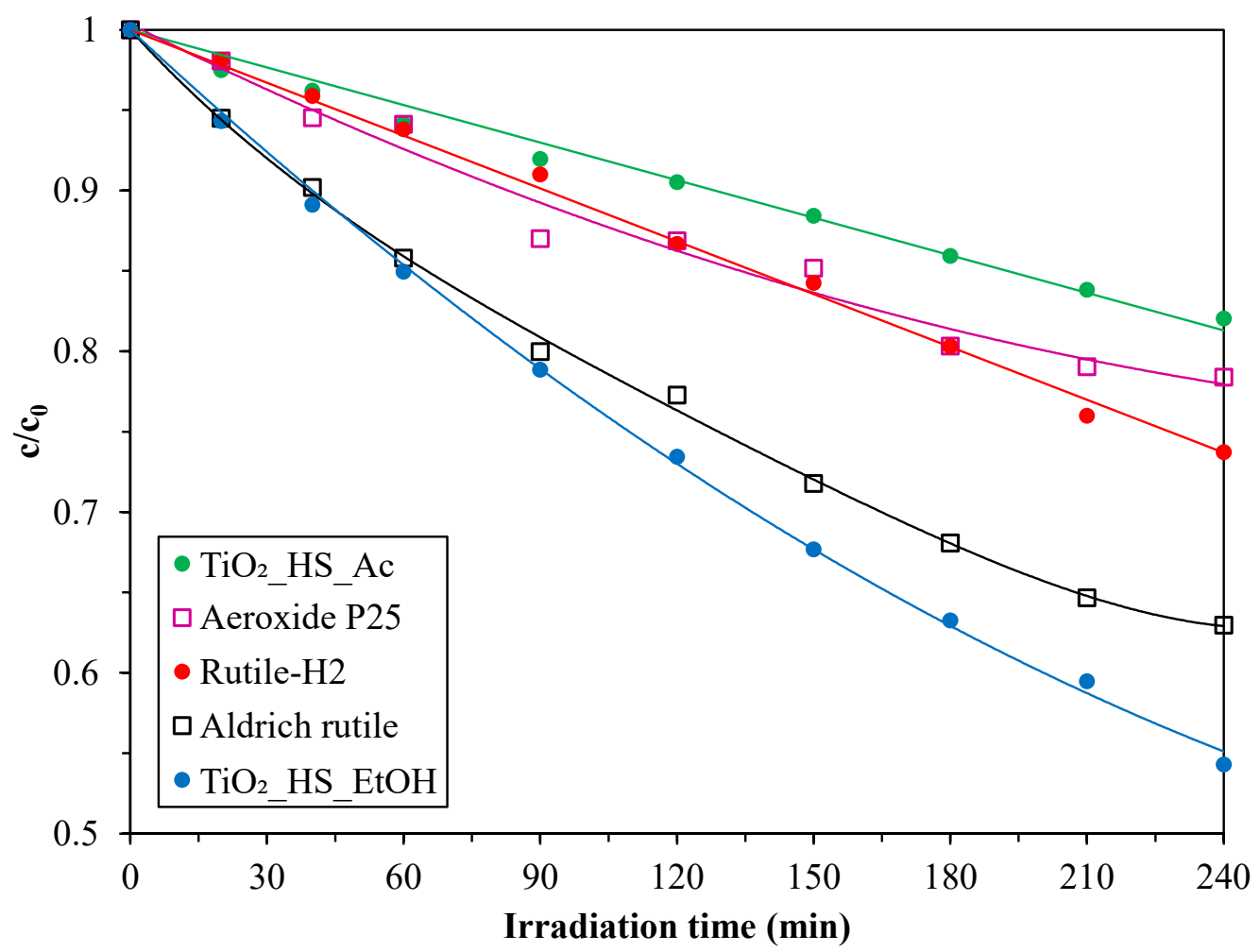

Figure 3. Photocatalytic degradation of the phenol model pollutant under visible light irradiation $\left(c_{\mathrm{phenol}}=0.1 \mathrm{mM}\right.$, $\left.\mathrm{c}_{\mathrm{TiO} 2}=1 \mathrm{~g} \cdot \mathrm{L}^{-1}\right)$.

The reasons for the observed photocatalytic activity order between the peroxo groupcontaining home-made Rutile-H2 and commercial Aldrich rutile, and the well-known commercial Aeroxide P25-which were used as references in this work-have already been described in detail in our previous publication [22]. As expected, sample $\mathrm{TiO}_{2}$ HS_Ac (containing predominantly anatase phase with no well-defined morphology) proved to be the least efficient under visible light irradiation. In contrast, the photocatalytic activity of sample $\mathrm{TiO}_{2}$ HS_EtOH (containing predominantly rutile phase with well-defined hollow spherical morphology) surpassed the photocatalytic activity of not only $\mathrm{TiO}_{2} \_\mathrm{HS} \_\mathrm{Ac}$ and Aeroxide P25 (as expected), but also the photocatalytic activity of home-made Rutile$\mathrm{H} 2$ and commercial Aldrich rutile references. Sample $\mathrm{TiO}_{2}$ HS_EtOH achieved such outstanding photocatalytic activity $\left(\mathrm{r}_{0, \text { phenol }}=3.9 \times 10^{-9} \mathrm{M} \cdot \mathrm{s}^{-1}\right)$ despite its lower specific surface area when compared to $\mathrm{TiO}_{2}{ }_{2} \mathrm{HS} \_\mathrm{Ac}\left(\mathrm{r}_{0, \text { phenol }}=1.2 \times 10^{-9} \mathrm{M} \cdot \mathrm{s}^{-1}\right)$. The difference is especially prominent when compared to Rutile-H2 (Table 1). It is worth highlighting 
that, under our applied experimental conditions, no pure rutile phase $\mathrm{TiO}_{2}$ has ever surpassed the photocatalytic activity of Aldrich rutile before our $\mathrm{TiO}_{2}$ HS_EtOH sample. The vastly superior photocatalytic activity of $\mathrm{TiO}_{2}$ HS_EtOH could be attributed partly to the dominance of the rutile phase and its enhanced light-harvesting capability, conveyed by the unique morphology [15]. However, considering the similar synthesis pathway of $\mathrm{TiO}_{2} \_\mathrm{HS} \_\mathrm{EtOH}$ compared to $\mathrm{TiO}_{2} \_\mathrm{HS} \_$Ac (the only difference being the CS purification solvent), vastly different characteristics (crystal phase composition, morphology, and photocatalytic activity) were observed, emphasizing the importance of the CS purification solvent on the properties of the resulting photocatalysts. Thus, to elucidate the effect caused by the application of either acetone or ethanol, Fourier transform infrared (FT-IR) spectroscopy measurements were carried out on the CSs, the $\mathrm{TiO}_{2}-\mathrm{CS}$ composites, and on the $\mathrm{TiO}_{2}$-HSs to seek surface-related differences (Figure 4).

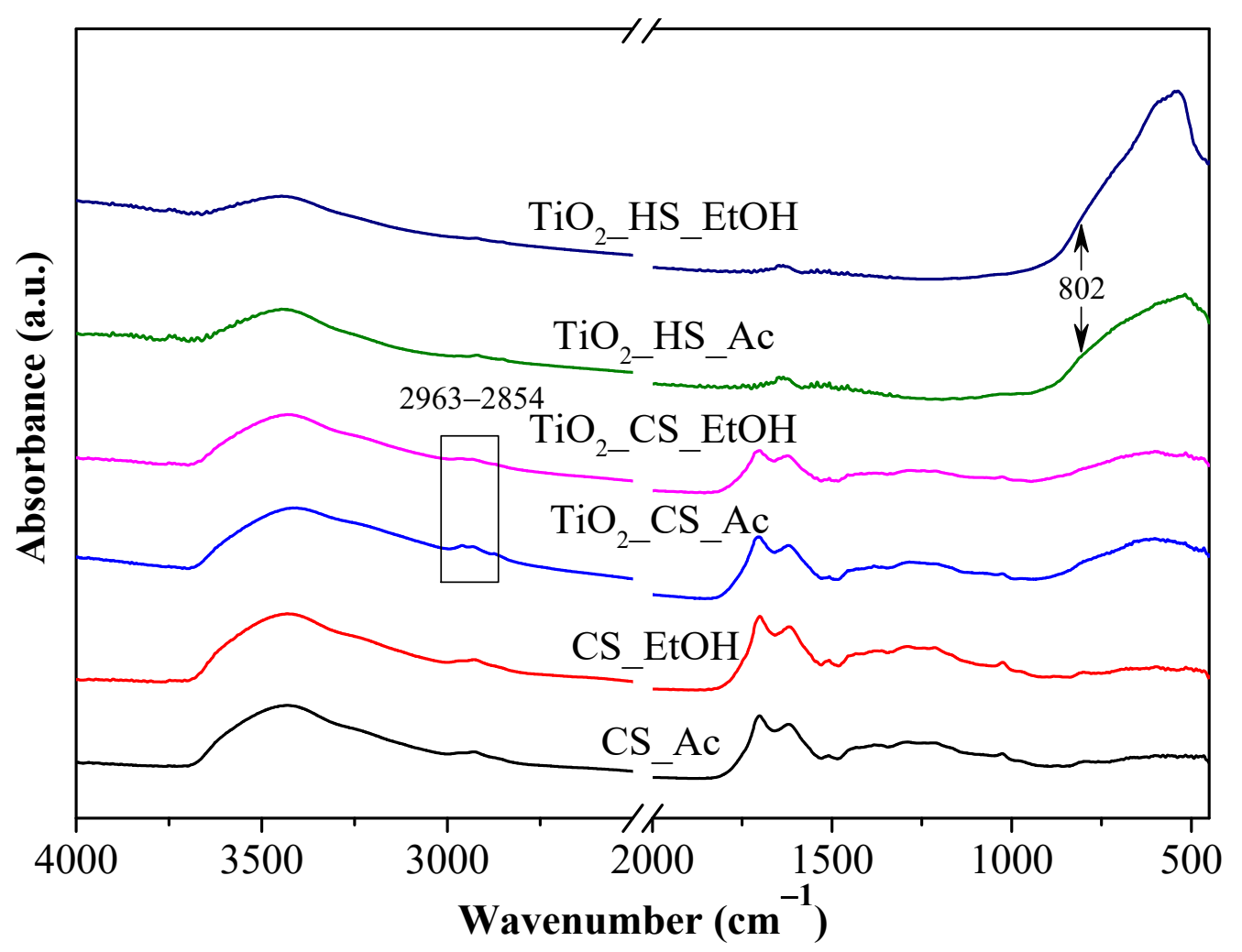

Figure 4. FT-IR spectra of the home-made CSs, $\mathrm{CS}-\mathrm{TiO}_{2}$ composites, and $\mathrm{TiO}_{2}-\mathrm{HSs}$.

In the FT-IR spectra, a broad band centered at $3400 \mathrm{~cm}^{-1}$ was observed together with a sharp band at $1630 \mathrm{~cm}^{-1}$, which can be associated with adsorbed water and stretching/bending vibrations of surface $\mathrm{OH}$ groups, respectively [24,25]. In the titania-containing samples, the bands around $540 \mathrm{~cm}^{-1}$ correspond to Ti-O bonds [26]. Bands at 2854, 2871, 2928, and $2963 \mathrm{~cm}^{-1}$ were more profound in $\mathrm{TiO}_{2}$ CS_Ac compared with $\mathrm{TiO}_{2}$ CS_EtOH, which were attributed to $\mathrm{CH}_{2}$ symmetric stretching, $\mathrm{CH}_{3}$ symmetric stretching, $\mathrm{C}-\mathrm{H}$ stretching, and $\mathrm{CH}_{3}$ asymmetric stretching vibrations, respectively [27]. Most importantly, in $\mathrm{TiO}_{2}$ HS_Ac, an additional band (i.e., a shoulder, partly covered by the Ti-O fingerprint region) was observed at $802 \mathrm{~cm}^{-1}$, compared with $\mathrm{TiO}_{2}$ HSS_EtOH. This can be attributed to the presence of carbonate species in the $\mathrm{TiO}_{2}$ lattice, which is characteristic of carbonmodified crystalline titania [28-30]. Based on these measurements, a plausible explanation was proposed for the differences that were observed between the $\mathrm{TiO}_{2}-\mathrm{HS}$ samples.

The properties (i.e., structure, morphology, and surface) of CS_Ac and CS_EtOH were very similar. After coating them with $\mathrm{TiO}_{2}$, a broad absorption band between $400-600 \mathrm{~cm}^{-1}$ appeared, as expected, which can be attributed to the transverse optical vibrations of Ti-O bonds [26]. The slight difference between the intensity of the bands in the $2854-2963 \mathrm{~cm}^{-1}$ 
region could not be attributed to the differences that were observed between the $\mathrm{TiO}_{2}$ HS samples. However, from the slight difference between their SSAs $\left(34 \mathrm{~m}^{2} \cdot \mathrm{g}^{-1}\right.$ for $\mathrm{TiO}_{2}$ CS_Ac and $27 \mathrm{~m}^{2} \cdot \mathrm{g}^{-1}$ for $\mathrm{TiO}_{2} \mathrm{CS}_{-} \mathrm{EtOH}$ ), it can be assumed that the $\mathrm{TiO}_{2}$ layer for $\mathrm{TiO}_{2}$ CS_EtOH was more compact. Moreover, based on their X-ray diffractograms, it was observed that these samples contained both amorphous and crystalline titania, with mixed crystal phases and small crystallite sizes. It was expected that these differences would influence the properties of the resulting titania after calcination. Accordingly, differences were observed between $\mathrm{TiO}_{2} \mathrm{HS}_{-} \mathrm{Ac}$ and $\mathrm{TiO}_{2}$ HS_EtOH in their morphology $\left(\mathrm{TiO}_{2} \mathrm{HS}_{-} \mathrm{EtOH}\right.$ was more regular), crystal phase composition $\left(\mathrm{TiO}_{2} \mathrm{HS}_{-} \mathrm{EtOH}\right.$ contained predominantly rutile, while $\mathrm{TiO}_{2}$ _HS_Ac contained predominantly anatase), and photocatalytic activity $\left(\mathrm{TiO}_{2}\right.$ HS_EtOH had much higher efficiency). Regarding the morphology, it was deduced that during calcination, $\mathrm{CO}_{2}$ could be released from the less compact $\mathrm{TiO}_{2}$ CS_Ac more rapidly, resulting in a higher number of damaged spheres for $\mathrm{TiO}_{2} \_\mathrm{HS} \_\mathrm{Ac}$ (Figure 2b). At the same time, due to the lower $\mathrm{SSA}_{\mathrm{A}} \mathrm{TiO}_{2} \mathrm{CS} \_\mathrm{EtOH}$, the elimination of CSs from the sample was slower, resulting in $\mathrm{TiO}_{2}$ HS_EtOH with a more regular morphology (Figure 2d). The difference in their crystal phase composition can be explained by the presence of carbon in the titania lattice. Based on the publication of A. Matthews, the presence of carbonate ions facilitates the formation of the anatase crystal phase [31]. As $\mathrm{CO}_{2}$ was released from $\mathrm{TiO}_{2}$ CS_Ac more rapidly, it could therefore be incorporated into the crystal lattice of $\mathrm{TiO}_{2}$ HSS_Ac. This was reinforced by the IR measurements, as the band at $802 \mathrm{~cm}^{-1}$ was more profound for $\mathrm{TiO}_{2}$ HS_Ac (Figure 4), indicating the presence of carbonate species in the titania lattice [28-30]. The crystal phase of the carbonate-containing titania samples in these publications was also predominantly anatase. Finally, the difference between the photocatalytic activity of $\mathrm{TiO}_{2} \_\mathrm{HS} \_\mathrm{Ac}$ and $\mathrm{TiO}_{2} \_\mathrm{HS} \_\mathrm{EtOH}$ (Figure 3) could also be attributed to the presence of carbonate species in $\mathrm{TiO}_{2}$ HS_Ac. It is known that carbonate ions act as a scavenger for $\cdot \mathrm{OH}$ radicals [32,33], which are the most important reactive oxygen species for the degradation of phenol. The higher photocatalytic activity of $\mathrm{TiO}_{2} \mathrm{HS}_{\mathrm{H}} \mathrm{EtOH}$ under visible light irradiation can also be attributed to the higher rutile content $[15,23]$ and more regular hollow spherical morphology since it facilitates the utilization of light [15], as previously mentioned. In summary, it was demonstrated that a seemingly insignificant parameter (such as the purification solvent) can have a major influence on the properties of the resulting titania.

\section{Materials and Methods}

\subsection{Materials}

CS templates were prepared using ordinary table sugar (sucrose, Magyar Cukor Zrt., Koronás $^{\mathrm{TM}}$, Kaposvár, Hungary), $\mathrm{NaOH}$ (Molar Chemicals, Halásztelek, Hungary; analytical reagent grade), acetone (Molar Chemicals, Halásztelek, Hungary; 99.96\%), and ethanol (VWR Chemicals, Debrecen, Hungary; $>96 \%$ ). For the $\mathrm{TiO}_{2}$ coating $\mathrm{Ti}(\mathrm{O}-\mathrm{nBu})_{4}$ (SigmaAldrich, Schnelldorf, Germany; reagent grade; 97\%), $\mathrm{HCl}$ (VWR Chemicals, Debrecen, Hungary; 37\%), $\mathrm{H}_{2} \mathrm{O}_{2}$ (Sigma-Aldrich, Schnelldorf, Germany; 30\%), and ultrapure water (Millipore Milli-Q, Budapest, Hungary) were used. For the evaluation of the photocatalytic activity, phenol (Spektrum 3D, Debrecen, Hungary; analytical grade) was used.

\subsection{Synthesis}

CS templates were synthesized in accordance with our previous publications $[21,34]$. In a Teflon-lined stainless-steel autoclave $\left(\mathrm{V}_{\text {tot }}=623 \mathrm{~mL}\right)$, an alkaline $(\mathrm{pH}=12), 0.15 \mathrm{M}$ sucrose solution $\left(\mathrm{V}_{\text {fill }}=180.7 \mathrm{~mL}\right)$ was prepared and subjected to hydrothermal treatment $\left(12 \mathrm{~h}, 180{ }^{\circ} \mathrm{C} ; \mathrm{V}_{\text {fill }} / \mathrm{V}_{\text {tot }}=29 \%\right)$. The as-prepared CSs were collected from the suspension and purified via centrifugation in 3 cycles with either acetone or ethanol to remove residual organic contaminants. For the purification of $1 \mathrm{~g}$ CS $80 \mathrm{~mL}$ solvent was used. Finally, the CSs were dried in air at $40{ }^{\circ} \mathrm{C}$ and ground in an agate mortar, prior to the coating process.

The synthesis method of the $\mathrm{TiO}_{2}$ coating was based on our previous paper [21]. In total, $3.5 \mathrm{~mL}$ Milli-Q water, $1.3 \mathrm{~mL} \mathrm{H}_{2} \mathrm{O}_{2}$, and $1.58 \mathrm{~mL} \mathrm{HCl}$ were added to a beaker followed 
by the dropwise addition of $\mathrm{Ti}(\mathrm{O}-\mathrm{nBu})_{4}$ precursor at a constant rate of $1 \mathrm{~mL} \cdot \mathrm{min}^{-1}$ under vigorous magnetic stirring. The bottom inorganic phase was separated via a separatory funnel after $60 \mathrm{~min}$ of phase separation; then, the previously prepared CS templates were added to it, which was then sonicated for 10 min to provide sufficient time for the coating process to take place. Lastly, the templates were eliminated from the as-prepared $\mathrm{TiO}_{2}$ CS composites via calcination using a tube furnace (Thermolyne 21100; Thermo Fischer Scientific, Prague, Czech Republic) at $400{ }^{\circ} \mathrm{C}$ for $4 \mathrm{~h}$. During this process, no additional air supply was provided. The solid white powder was then collected and ground in agate mortar prior to the textural characterization and photocatalytic activity experiments. Herein the samples are referred to as " $\mathrm{TiO}_{2} \_\mathrm{HS} \_\mathrm{X}$ ", where $\mathrm{X}$ is the applied solvent ("Ac" for acetone and " $\mathrm{E} \mathrm{tOH}^{\prime}$ " for ethanol) and 'HS' stands for 'hollow spheres'.

\subsection{Characterization Methods and Instrumentation}

Crystalline composition of titanium dioxide samples was investigated by XRD using a Rigaku Miniflex II diffractometer (Rigaku, Neu-Isenburg, Germany) with the following parameters: $\lambda_{\mathrm{Cu} \mathrm{K \alpha}}=0.15406 \mathrm{~nm}, 40 \mathrm{kV}$, and $30 \mathrm{~mA}, 20-40\left(2 \theta^{\circ}\right)$ region. Average primary crystal sizes were calculated using the Scherrer equation. Anatase-rutile weight fractions were estimated from their corresponding peak areas at $25.3\left(2 \theta^{\circ}\right)$ and $27.5\left(2 \theta^{\circ}\right)$, respectively. Morphology of the samples was observed via scanning and transmission electron microscopy (SEM and TEM) using a Hitachi S-4700 Type II (Hitachi, Tokyo, Japan) and a FEI TECNAI G2 20 X-Twin device (FEI, Hillsboro, OR, USA), respectively. The specific surface area was calculated following $\mathrm{N}_{2}$ adsorption measurements, carried out with a BELCAT-A device (Microtrac MRB, Osaka, Japan) using the Brunauer-Emmett-Teller (BET) method. Surface properties were investigated with a Jasco 6000 FT-IR (Jasco, Tokyo, Japan) spectrometer. The spectra were recorded applying $4 \mathrm{~cm}^{-1}$ spectral resolution in the $400-4000 \mathrm{~cm}^{-1}$ range.

\subsection{Photocatalytic Activity Experiments}

Photoactivity of the titania samples was investigated via the photocatalytic decomposition of phenol model pollutant $\left(\mathrm{c}_{0}=0.1 \mathrm{mM}\right)$ under visible light irradiation. The experiments were carried out in a double-walled glass vessel that was surrounded by four energy-saving, compact fluorescence lamps (Düwi 25920/R7S, 24W; Düwi Kft., Budapest, Hungary). The light intensity, which was measured by iron(III) oxalate actinometry, was $\mathrm{I}_{\text {Vis }}=1.07 \pm 0.03 \times 10^{-5}$ einstein $\cdot \mathrm{L}^{-1} \cdot \mathrm{s}^{-1}$. The spectrum of the lamps was slightly modified by circulating $1 \mathrm{M} \mathrm{NaNO}_{2}$ aqueous solution in the thermostat jacket $\left(\mathrm{T}=25.0{ }^{\circ} \mathrm{C}\right)$. $\mathrm{NaNO}_{2}$ solution absorbs ultraviolet (UV) photons; therefore, solely visible light irradiation was provided (Figure S2). The photocatalyst suspensions were stirred in the dark for $30 \mathrm{~min}$ to reach adsorption/desorption equilibrium. Constant magnetic stirring and air supply were provided during the tests. The concentration of phenol was measured via a high-performance liquid chromatograph (HPLC) equipped with a Lichrospher RP 18 column (Merck, Darmstadt, Germany) using 50-50\% methanol/water mixture as eluent $\left(\lambda_{\text {detection }}=210 \mathrm{~nm}\right)$. As references, our homemade "Rutile-H2" sample (a peroxo group-containing rutile $\mathrm{TiO}_{2}$ with high visible light excitability [35]) and commercial Sigma Aldrich (Schnelldorf, Germany) rutile and Aeroxide P25 were used.

\section{Conclusions}

The solvents used for the purification of the templates had a large influence on the properties of the resulting titania. Using acetone as solvent resulted in anatase phase $\mathrm{TiO}_{2}$ with no well-defined morphology, whereas the application of ethanol resulted in rutile phase $\mathrm{TiO}_{2}$ with well-defined hollow spherical morphology. The photocatalytic activity of the latter surpassed the efficiency of each investigated titania, both home-made and commercial references. The enhanced photocatalytic activity was attributed to the enhanced light-harvesting capability conveyed by the unique morphology to the crystal phase composition and the differences in the surface properties of the titania. Based on the 
infrared spectroscopy results, the purification solvent was identified to be a determining factor. It influenced the presence/absence of carbonate ions on the titania surface, which was deduced to be a significant parameter in shaping the characteristics of the resulting photocatalysts.

Supplementary Materials: The following are available online at https:/ /www.mdpi.com/2073-4 344/11/1/112/s1. Figure S1: X-ray diffraction patterns of carbon sphere templates purified either with acetone (CS_Ac) or ethanol (CS_EtOH) and their corresponding CS- $\mathrm{TiO}_{2}$ composites; Figure S2: Emission spectrum of the applied visible-light-emitting lamps that was modified with $\mathrm{NaNO}_{2}$ to absorb UV photons and provide solely visible light irradiation.

Author Contributions: T.G.: investigation, writing-original draft, conceptualization. K.K.: investigation. K.M.: investigation. K.B.: investigation. A.S.: investigation. G.V.: writing-review and editing. Z.P.: supervision, writing—original draft. K.H.: funding acquisition, writing—review and editing. All authors have read and agreed to the published version of the manuscript.

Funding: This study was financed by the NKFI-K-124212 project. T.G. is grateful for the financial support of the GINOP-2.3.2-15-2016-00013, NKFI-TNN-16-123631, and NTP-NFTÖ-20-B-0197 projects. Z.P. and K.M. acknowledge the Bolyai János scholarship provided by the Hungarian Academy of Sciences. Z.P. and G.V. were supported by the EFOP-3.6.2-16-2017-00010 project of the Hungarian State and the European Union.

Institutional Review Board Statement: Not applicable.

Informed Consent Statement: Not applicable.

Data Availability Statement: Data is contained within the article or Supplementary Material.

Conflicts of Interest: The authors declare no conflict of interest.

\section{References}

1. Herrmann, J.-M.; Matos, J.; Disdier, J.; Guillard, C.; Laine, J.; Malato, S.; Blanco, J. Solar photocatalytic degradation of 4chlorophenol using the synergistic effect between titania and activated carbon in aqueous suspension. Catal. Today 1999, 54, 255-265. [CrossRef]

2. Antoniou, M.G.; Dionysiou, D.D. Application of immobilized titanium dioxide photocatalysts for the degradation of creatinine and phenol, model organic contaminants found in NASA's spacecrafts wastewater streams. Catal. Today 2007, 124, 215-223. [CrossRef]

3. Veréb, G.; Manczinger, L.; Bozsó, G.; Sienkiewicz, A.; Forró, L.; Mogyorósi, K.; Hernádi, K.; Dombi, A. Comparison of the photocatalytic efficiencies of bare and doped rutile and anatase $\mathrm{TiO} 2$ photocatalysts under visible light for phenol degradation and E. coli inactivation. Appl. Catal. B Environ. 2013, 129, 566-574. [CrossRef]

4. Qamar, M.; Merzougui, B.; Anjum, D.; Hakeem, A.S.; Yamani, Z.H.; Bahnemann, D. Synthesis and photocatalytic activity of mesoporous nanocrystalline Fe-doped titanium dioxide. Catal. Today 2014, 230, 158-165. [CrossRef]

5. Rózsa, G.; Kozmér, Z.; Alapi, T.; Schrantz, K.; Takács, E.; Wojnárovits, L. Transformation of Z-thiacloprid by three advanced oxidation processes: Kinetics, intermediates and the role of reactive species. Catal. Today 2017, 284, 187-194. [CrossRef]

6. Alalm, M.G.; Tawfik, A.; Ookawara, S. Enhancement of photocatalytic activity of $\mathrm{TiO}_{2}$ by immobilization on activated carbon for degradation of pharmaceuticals. J. Environ. Chem. Eng. 2016, 4, 1929-1937. [CrossRef]

7. Vidal, A.; Díaz, A.I.; El Hraiki, A.; Romero, M.; Muguruza, I.; Senhaji, F.; González, J. Solar photocatalysis for detoxification and disinfection of contaminated water: Pilot plant studies. Catal. Today 1999, 54, 283-290. [CrossRef]

8. Malato, S.; Maldonado, M.I.; Fernández-Ibáñez, P.; Oller, I.; Polo, I.; Sánchez-Moreno, R. Decontamination and disinfection of water by solar photocatalysis: The pilot plants of the Plataforma Solar de Almeria. Mater. Sci. Semicond. Process. 2016, 42, 15-23. [CrossRef]

9. Pelaez, M.; Nolan, N.T.; Pillai, S.C.; Seery, M.K.; Falaras, P.; Kontos, A.G.; Dunlop, P.S.M.; Hamilton, J.W.J.; Byrne, J.A.; O'Shea, K.; et al. A review on the visible light active titanium dioxide photocatalysts for environmental applications. Appl. Catal. B Environ. 2012, 125, 331-349. [CrossRef]

10. Xiang, L.; Zhao, X. Wet-Chemical Preparation of $\mathrm{TiO}_{2}$-Based Composites with Different Morphologies and Photocatalytic Properties. Nanomaterials 2017, 7, 310. [CrossRef]

11. Fernández-Ibáñez, P.; Polo-López, M.I.; Malato, S.; Wadhwa, S.; Hamilton, J.W.J.; Dunlop, P.S.M.; D'Sa, R.; Magee, E.; O'Shea, K.; Dionysiou, D.D.; et al. Solar photocatalytic disinfection of water using titanium dioxide graphene composites. Chem. Eng. J. 2015, 261,36-44. [CrossRef]

12. Balayeva, N.O.; Fleisch, M.; Bahnemann, D.W. Surface-grafted WO3/TiO2 photocatalysts: Enhanced visible-light activity towards indoor air purification. Catal. Today 2018, 313, 63-71. [CrossRef] 
13. Bao, Y.; Guo, R.; Gao, M.; Kang, Q.; Ma, J. Morphology control of 3D hierarchical urchin-like hollow SiO2@TiO2 spheres for photocatalytic degradation: Influence of calcination temperature. J. Alloys Compd. 2021, 853, 157202. [CrossRef]

14. Ibhadon, A.; Fitzpatrick, P. Heterogeneous Photocatalysis: Recent Advances and Applications. Catalysts 2013, 3, 189-218. [CrossRef]

15. Li, H.; Bian, Z.; Zhu, J.; Zhang, D.; Li, G.; Huo, Y.; Li, H.; Lu, Y. Mesoporous titania spheres with tunable chamber stucture and enhanced photocatalytic activity. J. Am. Chem. Soc. 2007, 129, 8406-8407. [CrossRef]

16. Lyu, J.; Zhou, L.; Shao, J.; Zhou, Z.; Gao, J.; Dong, Y.; Wang, Z.; Li, J. TiO2 hollow heterophase junction with enhanced pollutant adsorption, light harvesting, and charge separation for photocatalytic degradation of volatile organic compounds. Chem. Eng. J. 2020, 391, 123602. [CrossRef]

17. Ao, Y.; Xu, J.; Fu, D.; Yuan, C. A simple method for the preparation of titania hollow sphere. Catal. Commun. 2008, 9, 2574-2577. [CrossRef]

18. Zheng, M.; Cao, J.; Chang, X.; Wang, J.; Liu, J.; Ma, X. Preparation of oxide hollow spheres by colloidal carbon spheres. Mater. Lett. 2006, 60, 2991-2993. [CrossRef]

19. Sun, X.; Li, Y. Colloidal carbon spheres and their core/shell structures with noble-metal nanoparticles. Angew. Chem. Int. Ed. Engl. 2004, 43, 597-601. [CrossRef]

20. Mahyar, A.; Amani-Ghadim, A.R. Influence of solvent type on the characteristics and photocatalytic activity of TiO2 nanoparticles prepared by the sol-gel method. Micro Nano Lett. 2011, 6, 244. [CrossRef]

21. Gyulavari, T.; Vereb, G.; Pap, Z.; Reti, B.; Baan, K.; Todea, M.; Magyari, K.; Szilagyi, I.M.; Hernadi, K. Utilization of Carbon Nanospheres in Photocatalyst Production: From Composites to Highly Active Hollow Structures. Materials 2019, $12,2537$. [CrossRef] [PubMed]

22. Gyulavári, T.; Veréb, G.; Pap, Z.; Dombi, A.; Hernádi, K. Associating low crystallinity with peroxo groups for enhanced visible light active photocatalysts. Catal. Today 2018, 313, 231-238. [CrossRef]

23. Noh, J.; Yi, M.; Hwang, S.; Im, K.M.; Yu, T.; Kim, J. A facile synthesis of rutile-rich titanium oxide nanoparticles using reverse micelle method and their photocatalytic applications. J. Ind. Eng. Chem. 2016, 33, 369-373. [CrossRef]

24. Orlikowski, J.; Tryba, B.; Ziebro, J.; Morawski, A.W.; Przepiórski, J. A new method for preparation of rutile phase titania photoactive under visible light. Catal. Commun. 2012, 24, 5-10. [CrossRef]

25. Ye, X.; Zheng, C.; Ma, L.; Huang, X. Microemulsion-assisted hydrothermal preparation and infrared radiation property of TiO2 nanomaterials with tunable morphologies and crystal form. Mater. Sci. Semicond. Process. 2015, 31, 295-301. [CrossRef]

26. Busani, T.; Devine, R.A.B. Dielectric and infrared properties of TiO2 films containing anatase and rutile. Semicond. Sci. Technol. 2005, 20, 870-875. [CrossRef]

27. Talari, A.C.S.; Martinez, M.A.G.; Movasaghi, Z.; Rehman, S.; Rehman, I.U. Advances in Fourier transform infrared (FTIR) spectroscopy of biological tissues. Appl. Spectrosc. Rev. 2016, 52, 456-506. [CrossRef]

28. Etacheri, V.; Michlits, G.; Seery, M.K.; Hinder, S.J.; Pillai, S.C. A highly efficient $\mathrm{TiO}_{2-x} \mathrm{C}_{\mathrm{x}}$ nano-heterojunction photocatalyst for visible light induced antibacterial applications. ACS Appl. Mater. Interfaces 2013, 5, 1663-1672. [CrossRef]

29. Shao, P.; Tian, J.; Zhao, Z.; Shi, W.; Gao, S.; Cui, F. Amorphous $\mathrm{TiO}_{2}$ doped with carbon for visible light photodegradation of rhodamine B and 4-chlorophenol. Appl. Surf. Sci. 2015, 324, 35-43. [CrossRef]

30. Sakthivel, S.; Kisch, H. Daylight photocatalysis by carbon-modified titanium dioxide. Angew. Chem. Int. Ed. Engl. 2003, 42, 4908-4911. [CrossRef]

31. Matthews, A. The crystallization of anatase and rutile from amorphous titanium dioxide under hydrothermal condition. Am. Mineral. 1976, 61, 419-424.

32. Buxton, G.V.; Greenstock, C.L.; Helman, W.P.; Ross, A.B. Critical Review of rate constants for reactions of hydrated electrons, hydrogen atoms and hydroxyl radicals $(\mathrm{OH} / \mathrm{O}-$ in Aqueous Solution. J. Phys. Chem. Ref. Data 1988, 17, 513-886. [CrossRef]

33. Merouani, S.; Hamdaoui, O.; Saoudi, F.; Chiha, M.; Petrier, C. Influence of bicarbonate and carbonate ions on sonochemical degradation of Rhodamine B in aqueous phase. J. Hazard. Mater. 2010, 175, 593-599. [CrossRef] [PubMed]

34. Réti, B.; Kiss, G.I.; Gyulavári, T.; Baan, K.; Magyari, K.; Hernadi, K. Carbon sphere templates for TiO2 hollow structures: Preparation, characterization and photocatalytic activity. Catal. Today 2017, 284, 160-168. [CrossRef]

35. Gyulavári, T.; Pap, Z.; Kovács, G.; Baia, L.; Todea, M.; Hernádi, K.; Veréb, G. Peroxo group enhanced nanorutile as visible light active photocatalyst. Catal. Today 2017, 284, 129-136. [CrossRef] 